\section{(A) Check for updates}

Cite this: Org. Chem. Front., 2017, 4, 1517

Received 30th March 2017, Accepted 23rd April 2017

DOI: $10.1039 / \mathrm{c} 7 \mathrm{qo} 00250 \mathrm{e}$

rsc.li/frontiers-organic

\title{
Pincer cobalt complex-catalyzed Z-selective hydrosilylation of terminal alkynes $\uparrow$
}

\begin{abstract}
Xiaoyong Du, Wenjun Hou, Yanlu Zhang and Zheng Huang*
A phosphine-iminopyridine $\left(\mathrm{P}^{C} \mathrm{NN}\right)$ cobalt-catalyzed Z-selective hydrosilylation of terminal alkynes with $\mathrm{Ph}_{2} \mathrm{SiH}_{2}$ has been developed for the synthesis of $(Z)$ - $\beta$-vinylsilanes with high regio- and stereoselectivity and wide functional group tolerance. Furthermore, the Co-catalyzed hydrosilylations of unsymmetrical arylalkyl disubstituted internal alkynes afford syn-addition products with unique regioselectivity: the silyl group is added to the alkyl-substituted carbon, instead of the aryl-substituted carbon. The (Z)- $\beta$-vinylsilane products are further applied to Pd-catalyzed Hiyama-Denmark cross-couplings for stereoselective synthesis of $(Z)$-disubstituted alkenes.
\end{abstract}

\section{Introduction}

Transition metal-catalyzed hydrosilylation of alkynes with hydrosilanes is one of the most atom-economical approaches to access vinylsilanes, ${ }^{1}$ which are valuable intermediates in organic synthesis. ${ }^{2}$ The hydrosilylation of a terminal alkyne can generate three possible products, $(E)-\beta-, \quad(Z)-\beta-$, and $\alpha$-vinylsilanes (Scheme 1a), and thus controlling the regio- and stereoselectivity is a key issue during the $\mathrm{H}-\mathrm{Si}$ addition process. The selective synthesis of $(Z)$ - $\beta$-vinylsilanes is considered to be more challenging than the formation of the thermodynamically more stable $(E)$ - $\beta$-isomers. Indeed, many transition metal-catalyzed hydrosilylation reactions selectively form (E)- $\beta$-vinylsilanes. ${ }^{3}$ Nevertheless, a number of catalysts using noble-metals, such as $\mathrm{Rh},{ }^{4} \mathrm{Ir}^{4 g, 5}$ and $\mathrm{Ru},{ }^{6}$ have been developed for the $(Z)-\beta$-selective hydrosilylation of terminal alkynes.

Over the past decade, the low abundance, high cost, and the environmental concerns associated with the noble metals have spurred extensive studies toward developing earth-abundant base-metal alternatives. ${ }^{7}$ So far, $\mathrm{Fe},{ }^{8} \mathrm{Co}^{9}{ }^{9}$ and $\mathrm{Ni}^{10}$ complexes have been proven effective for alkyne hydrosilylation, but only bis(imino)pyridine iron complexes gave high $(Z)-\beta$-selectivity in the hydrosilylations of two terminal alkyne substrates. ${ }^{8 c, d}$ Very recently, several groups reported that cobalt complexes could catalyze the hydrosilylation of terminal alkynes with high $\alpha$ - or $(E)$ - $\beta$-selectivity. In 2014, Deng developed a carbene-ligated $\mathrm{Co}(\mathrm{I})$ complex and applied it to the

State Key Laboratory of Organometallic Chemistry, Shanghai Institute of Organic Chemistry, 345 Lingling Road, Shanghai, 200032, China.

E-mail: huangzh@sioc.ac.cn; Fax: +86 5492 5533; Tel: +86 54925522

$\dagger$ Electronic supplementary information (ESI) available. See DOI: 10.1039/ c7qo00250e a) Regio- and stereoselectivity in hydrosilylation of terminal alkyne

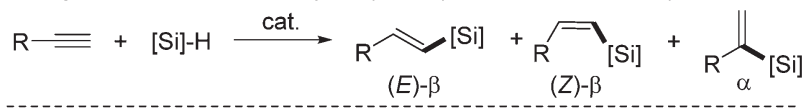

b) Deng and Thomas: high (E)- $\beta$-selectivity

$$
\mathrm{R}=+[\mathrm{Si}]-\mathrm{H} \quad \frac{\mathrm{Co}(\mathrm{IAd})\left(\mathrm{PPh}_{3}\right)\left(\mathrm{CH}_{2} \mathrm{TMS}\right)}{\operatorname{or}\left({ }^{\mathrm{Mes} P D I}\right) \mathrm{CoCl}_{2} / \mathrm{NaOtBu}} \overbrace{(E)-\beta}^{[\mathrm{Si}]}
$$

c) Huang and Lu: high $\alpha$-selectivity

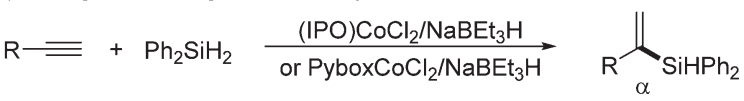

d) This work: high (Z)- $\beta$-selectivity

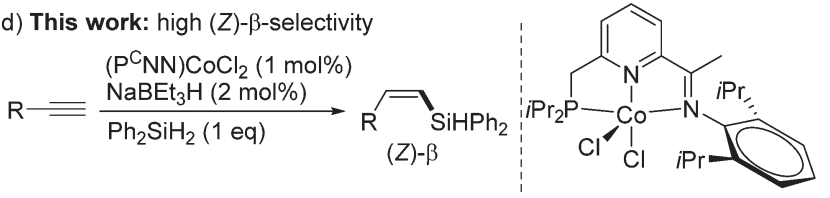

Scheme 1 Cobalt-catalyzed hydrosilylation of terminal alkynes.

hydrosilylation of alkynes with high (E)- $\beta$-selectivities (Scheme 1b). ${ }^{11}$ Thomas described a combination of the $\left({ }^{\mathrm{Mes}} \mathrm{PDI}\right) \mathrm{CoCl}_{2}$ complex of bis(imino)pyridine and $\mathrm{NaO} t \mathrm{Bu}$ for (E)- $\beta$-selective hydrosilylation with 1-hexyne with $\mathrm{PhSiH}_{3}$ (Scheme 1b). ${ }^{12}$ In 2016, $\mathrm{Lu}^{13}$ and our group ${ }^{14}$ independently reported Co complexes of iminopyridine-oxazoline (IPO) or Pybox ligands for the $\alpha$-selective hydrosilylation of terminal aryl alkynes with $\mathrm{Ph}_{2} \mathrm{SiH}_{2}$ (Scheme 1c). However, the use of cobalt complexes for the hydrosilylation of terminal alkynes with (Z)- $\beta$-selectivity is rare ${ }^{15}$ During the submission of this manuscript, Ge reported a bis(imino)pyridine cobalt-catalyzed $Z$-selective hydrosilylation of terminal alkynes with $\mathrm{PhSiH}_{3}{ }^{16}$ Herein, we describe a highly $Z$-selective hydrosilylation of terminal alkynes with $\mathrm{Ph}_{2} \mathrm{SiH}_{2}$ using a $\left(\mathrm{P}^{C} \mathrm{NN}\right) \mathrm{CoCl}_{2} / \mathrm{NaBEt}_{3} \mathrm{H}$ catalyst system (Scheme 1a), which has been previously developed by our group for the Markovnikov hydrosilylation of term- 
inal alkenes. ${ }^{17}$ Moreover, the $\left(\mathrm{P}^{C} \mathrm{NN}\right) \mathrm{Co}$ catalyst effects the hydrosilylation of internal alkynes, and intriguingly, the reactions of arylalkyl disubstituted alkynes produce vinylsilanes containing the silyl unit at the alkyl-substituted olefinic carbon, rather than the aryl-substituted one. The $(Z)$ - $\beta$-vinylsilane products can undergo Pd-catalyzed HiyamaDenmark cross-couplings to form $(Z)$-disubstituted alkenes.

\section{Results and discussion}

We commenced our studies by examining the $\mathrm{P}^{C} \mathrm{NN}$ ligandsupported $\mathrm{Fe}$ and $\mathrm{Co}$ catalysts for the hydrosilylation of a simple aliphatic alkyne, 1-hexyne (3a), with $\mathrm{Ph}_{2} \mathrm{SiH}_{2}$ as the silicon source. The results are summarized in Table 1. Using $\mathrm{NaBEt}_{3} \mathrm{H}(2 \mathrm{~mol} \%)$ as the activator, both $t \mathrm{Bu}$ - and iPr-substituted Fe complexes, $\left({ }^{t B u} \mathrm{P}^{C} \mathrm{NN}^{\mathrm{iPr}}\right) \mathrm{FeCl}_{2} \quad$ (1a, 1 mol\%) and $\left.{ }^{\mathrm{iPr}} \mathrm{P}^{C} \mathrm{NN}^{\mathrm{iPr}}\right) \mathrm{FeCl}_{2}$ (1) $\left.1 \mathrm{~mol} \%\right)$, were inactive for the hydrosilylation (entries 1 and 2). However, 1-hexyne (1.2 equiv.) reacted with $\mathrm{Ph}_{2} \mathrm{SiH}_{2}$ to give $(Z)$ - $\beta$-vinylsilane $4 \mathbf{a}$ and $(E)$ - $\beta$-vinylsilane 5a when the Co analogues were employed. Using the most sterically hindered complex $2 \mathrm{a}(1 \mathrm{~mol} \%)$ bearing a $t \mathrm{Bu}-$ substituted phosphino group and iPr substituents at the 2,6-positions of the $\mathrm{N}$-aryl ring, the hydrosilylation in THF at $25{ }^{\circ} \mathrm{C}$ gave $13 \%$ 4a and 18\% 5a after $24 \mathrm{~h}$ (entry 3). Reducing the steric hindrance of the $\mathrm{P}^{C} \mathrm{NN}$ ligands resulted in a significant improvement of the activity and selectivity for the desired

Table $1 \quad\left(\mathrm{P}^{\mathrm{C}} \mathrm{NN}\right) \mathrm{Fe}$ and $\left(\mathrm{P}^{\mathrm{C}} \mathrm{NN}\right) \mathrm{Co}$ complex-catalyzed hydrosilylation of 1-hexyne with hydrosilanes ${ }^{a}$

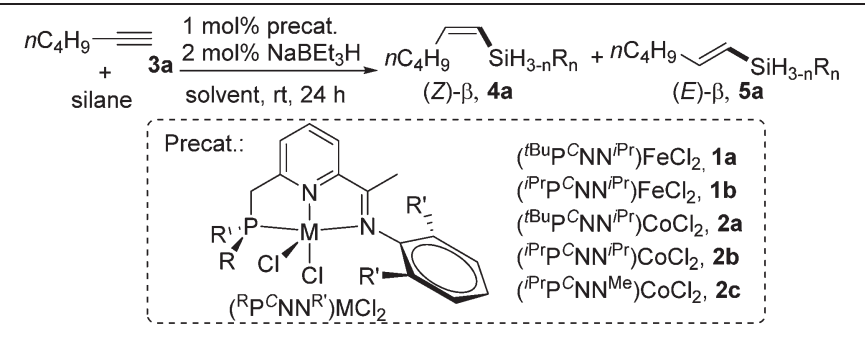

\begin{tabular}{|c|c|c|c|c|c|c|}
\hline \multirow[b]{2}{*}{ Entry } & \multirow[b]{2}{*}{ Cat. } & \multirow[b]{2}{*}{ Silane } & \multirow[b]{2}{*}{ Solvent } & \multirow[b]{2}{*}{$3 \mathbf{a} /[\mathrm{Si}]$} & \multicolumn{2}{|c|}{ Yield [\%] } \\
\hline & & & & & $4 a$ & $5 a$ \\
\hline 1 & $1 \mathrm{a}$ & $\mathrm{Ph}_{2} \mathrm{SiH}_{2}$ & THF & 1.2 & 0 & 0 \\
\hline 2 & $1 b$ & $\mathrm{Ph}_{2} \mathrm{SiH}_{2}$ & THF & 1.2 & 0 & 0 \\
\hline 3 & $2 a$ & $\mathrm{Ph}_{2} \mathrm{SiH}_{2}$ & THF & 1.2 & 13 & 18 \\
\hline 4 & $2 \mathbf{b}$ & $\mathrm{Ph}_{2} \mathrm{SiH}_{2}$ & THF & 1.2 & 85 & 3 \\
\hline 5 & $2 c$ & $\mathrm{Ph}_{2} \mathrm{SiH}_{2}$ & THF & 1.2 & 83 & 3 \\
\hline 6 & $2 \mathbf{b}$ & $\mathrm{Ph}_{2} \mathrm{SiH}_{2}$ & None & 1.5 & 95 & 1 \\
\hline $7^{b}$ & $2 \mathbf{b}$ & $\mathrm{Ph}_{2} \mathrm{SiH}_{2}$ & None & 1.5 & 0 & 0 \\
\hline $8^{c}$ & $2 \mathbf{b}$ & $\mathrm{Ph}_{2} \mathrm{SiH}_{2}$ & None & 1.5 & 0 & 0 \\
\hline 9 & $2 \mathbf{b}$ & $(\mathrm{EtO})_{3} \mathrm{SiH}$ & None & 1.5 & $<5$ & $<5$ \\
\hline 10 & $2 \mathbf{b}$ & $\mathrm{MD}^{\prime} \mathrm{M}$ & None & 1.5 & 0 & 0 \\
\hline 11 & $2 \mathbf{b}$ & $\mathrm{Et}_{3} \mathrm{SiH}$ & None & 1.5 & 0 & 0 \\
\hline 12 & $2 \mathbf{b}$ & $\mathrm{PhMe}_{2} \mathrm{SiH}$ & None & 1.5 & 0 & 0 \\
\hline 13 & $2 \mathbf{b}$ & $\mathrm{PhSiH}_{3}$ & None & 1.5 & 50 & 45 \\
\hline
\end{tabular}

${ }^{a}$ Reaction conditions: $3 \mathrm{a}(0.72-0.9 \mathrm{mmol})$ and silane $(0.6 \mathrm{~mol})$ in THF $(1 \mathrm{~mL})$ or under neat conditions at $25^{\circ} \mathrm{C}$. The yields were determined by ${ }^{1} \mathrm{H}$ NMR spectroscopy. ${ }^{b}$ Without precat. ${ }^{c}$ Without NaHBEt $_{3}$.
(Z)- $\beta$-product. The reactions using complexes $\left({ }^{\mathrm{iPr}} \mathrm{P}^{C} \mathrm{NN}^{\mathrm{iPr}}\right) \mathrm{CoCl}_{2}$ 2b and ( $\left.{ }^{\mathrm{iPr}} \mathrm{P}^{C} \mathrm{NN}^{\mathrm{Me}}\right) \mathrm{CoCl}_{2}$ 2c containing iPr-substituted phosphino groups formed $\mathbf{4 a}$ in $85 \%$ and $83 \%$ yield; $\alpha$-vinylsilane was not observed in both cases (entries 4 and 5).

Further optimizations were conducted to improve the selectivity for cis-vinylsilane. The best Z-selectivity was obtained when the reaction occurred under solvent-free conditions using a 1.5:1 ratio of $3 \mathrm{a}: \mathrm{Ph}_{2} \mathrm{SiH}_{2}$ in the presence of $1 \mathrm{~mol} \%$ of $\mathbf{2 b}$ and $2 \mathrm{~mol}^{\circ}$ of $\mathrm{NaHBEt}_{3}$; the run at $25{ }^{\circ} \mathrm{C}$ for $24 \mathrm{~h}$ produced $(Z)$-vinylsilane $\mathbf{4 a}$ in $95 \%$ yield with the $Z / E$ stereoselectivity of 95:1 (entry 6). A control experiment without the precatalyst $\mathbf{2 b}$, but with $\mathrm{NaBEt}_{3} \mathrm{H}$, gave no hydrosilylation product (entry 7), and another control without $\mathrm{NaHBEt}_{3}$ indicated that the addition of the activator was necessary for the catalysis (entry 8). Finally, we explored the catalytic performance of this Co catalyst for hydrosilylations with primary and tertiary hydrosilanes. Tertiary silanes (EtO) ${ }_{3} \mathrm{SiH}, \mathrm{MD}^{\prime} \mathrm{M}$ (1,1,1,3,5,5,5-heptamethyltrisiloxane), $\mathrm{Et}_{3} \mathrm{SiH}$ and $\mathrm{PhMe}_{2} \mathrm{SiH}$ were unreactive under the reaction conditions (entries 9-12). Although the reaction with $\mathrm{PhSiH}_{3}$ gave the anti-Markovnikov products in high yield (95\% totally), the stereoselectivity was low $(Z / E=\sim 1: 1)$ (entry 13).

To evaluate the scope of the Co-catalyzed alkyne hydrosilylation, the reactions with a variety of functionalized terminal alkynes and a number of internal alkynes were carried out using $\mathbf{2 b}$ as the precatalyst. The results are summarized in Table 2. All reactions with $\mathrm{Ph}_{2} \mathrm{SiH}_{2}$ proceeded to completion within $24 \mathrm{~h}$ at room temperature under solvent-free conditions. For terminal alkyne substrates, most reactions were highly selective for the formation of the $(Z)$ - $\beta$-vinylsilane products $(Z / E>95: 5)$. Linear terminal alkynes gave the corresponding products $\mathbf{4 a - d}$ in moderate-to-high isolated yield with excellent selectivity. 3-Cyclohexyl-1-propyne 3e and 3-cyclopentyl-1-propyne $3 f$ underwent hydrosilylations in useful yields and high selectivities. The catalyst is compatible with terminal alkynes bearing various functional groups, including chloride $(\mathbf{4 g})$, nitrile $(\mathbf{4 h})$, tertiary amine $(\mathbf{4 i}, \mathbf{4 j})$, amide (4k) and even ester (4o). Aliphatic alkynes containing protecting groups, such as silylether $(\mathbf{4 1}, \mathbf{4 m})$ and tosylate $(\mathbf{4 n}, 88 \%)$, afforded the desired $(Z)$ - $\beta$-vinylsilanes in high yields and high selectivities. Aryl terminal alkynes are unreactive under the catalytic conditions, as demonstrated by the full recovery of the alkyne in the reaction of phenylacetylene with $\mathrm{Ph}_{2} \mathrm{SiH}_{2}$.

Internal alkynes underwent the hydrosilylation reactions under the catalytic conditions to form the products in good-tohigh yields. The hydrosilylation of symmetric dialkyl-substituted alkynes $(\mathbf{3 p}, \mathbf{3 q})$ occurred to form the syn-addition products in high yields $(\mathbf{4} \mathbf{p}, \mathbf{4 q})$. Next, we turned our attention to the more challenging unsymmetrical internal alkynes. The unsymmetrical dialkyl-substituted alkynes with different steric properties, such as 1-tert-butyl-1-propyne (3r) and 4-methylpent-2-yne (3s), were suitable for the selective hydrosilylation, producing the syn-addition products $4 \mathbf{r}$ and $4 \mathbf{s}$ with the incorporation of the silyl group into the less sterically demanding sp-hybridised carbon. The reaction of arylalkyl disubstituted alkynes (3t-v) gave the products in 91-94\% yields (4t-v). 
Table 2 Cobalt-catalyzed hydrosilylation of various terminal and internal alkynes with $\mathrm{Ph}_{2} \mathrm{SiH}_{2}{ }^{a}$

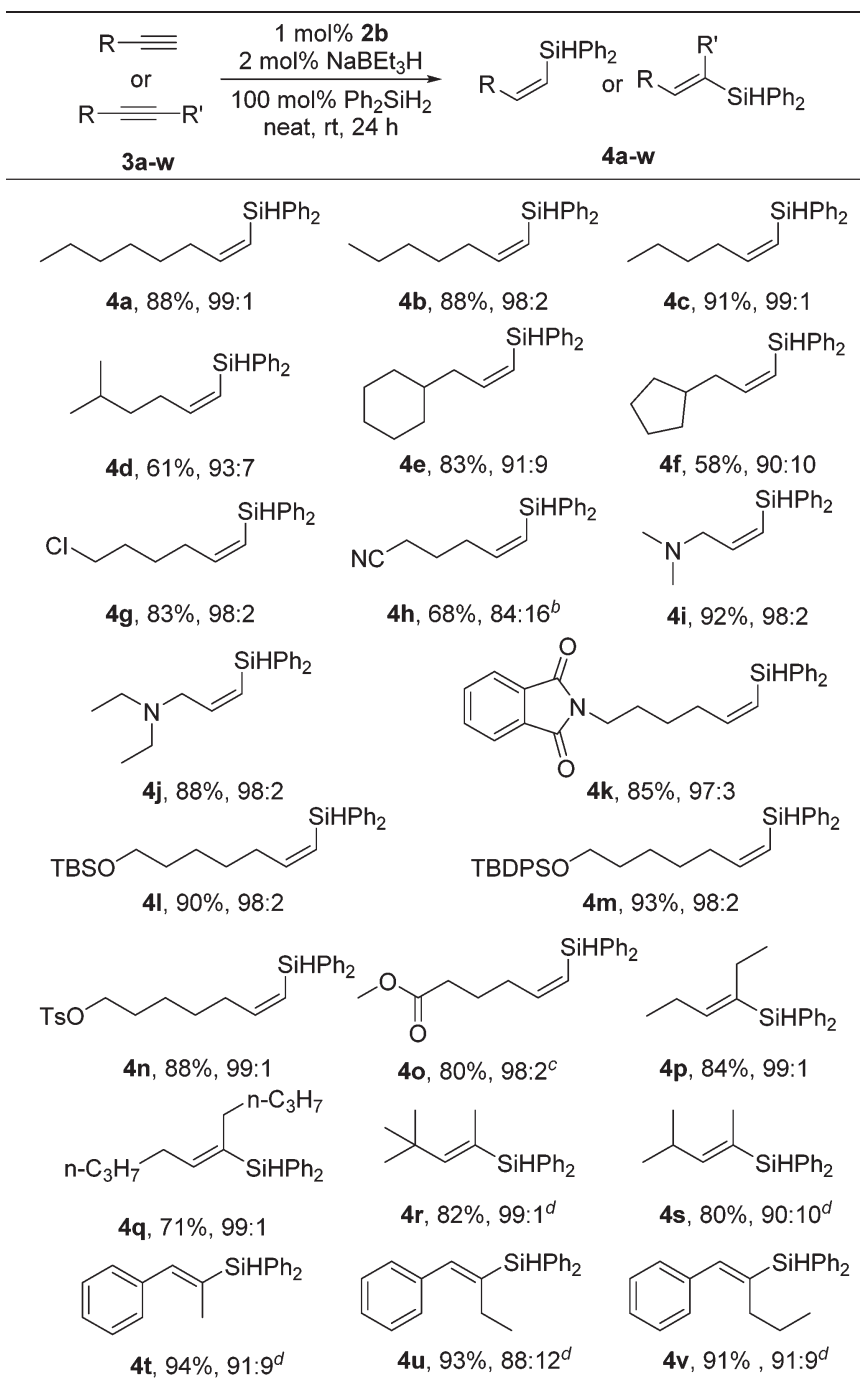

${ }^{a}$ Reaction conditions: $\mathrm{Ph}_{2} \mathrm{SiH}_{2}(0.6 \mathrm{mmol})$ and alkyne $(0.9 \mathrm{mmol})$ at $25{ }^{\circ} \mathrm{C}$. Yield of isolated products. $Z / E$ ratios of isolated products were determined by ${ }^{1} \mathrm{H}$ NMR spectroscopy. ${ }^{b}$ With $1.2 \mathrm{mmol} 3 \mathbf{3 h}$. A $84: 16$ $Z$ - $\beta / \alpha$ ratio was determined by ${ }^{1} \mathrm{H}$ NMR spectroscopy. ${ }^{c}$ With 2 mol\% $2 \mathbf{b}$ and $4 \mathrm{~mol} \% \mathrm{NaBEt}_{3} \mathrm{H}$. ${ }^{d}$ Regioselectivities determined by ${ }^{1} \mathrm{H}$ NMR spectroscopy.

Noteworthily, the processes exhibited good regioselectivities, furnishing tri-substituted olefins with the $\mathrm{Ph}_{2} \mathrm{HSi}$ unit selectively added to the alkyl-substituted olefinic carbon, which is in contrast to previous reports on Co-catalyzed hydrosilylations of arylalkyl disubstituted alkynes that yielded vinylsilanes with the $\mathrm{Si}$ atom adjacent to the aryl group..$^{9 e, 11,13}$

Due to their high stability, non-toxicity, and ease of handling, vinylsilanes have become valuable intermediates for Pdcatalyzed Hiyama-Denmark cross-couplings. ${ }^{18}$ However, the silane reagents used in the coupling reactions often require heteroatom substituent(s) (e.g., O or F) to make the Si atom feasible toward activation with a base or fluoride source. ${ }^{19}$ To this end, it is of interest to develop conditions for cross-coup- lings of our (Z)-vinylsilane products bearing the $\mathrm{Ph}_{2} \mathrm{HSi}$ moiety. ${ }^{20}$ After a screening of various mono- and bisphosphine ligands (see the ESI $\dagger$ ), we identified the Pd catalyst generated from $\mathrm{Pd}(\mathrm{OAc})_{2}(10 \mathrm{~mol} \%)$ and 1,4-bis(diphenylphosphino) butane (dppb, $12 \mathrm{~mol} \%$ ) was effective for stereoselective couplings of $(Z)$-vinylsilane (4) with aryl iodides using TBAF as the activator ( 2 equiv.). Most reactions occurred at $30{ }^{\circ} \mathrm{C}$ to form the cis-1,2-disubstituted alkenes in high yields and high stereoselectivities (Table 3). The electrophiles 6 bearing both electron-donating and -withdrawing groups were suitable coupling partners. Functionalized groups, such as ester (7a), ketone (7b), tertiary amine (7d) and nitrile $(7 \mathbf{j})$ could be tolerated. The reaction of $\mathbf{6 c}$ containing a nitro group provided the coupling product 7c in high yield, albeit with relatively low $Z$-selectivity (75:25). Aryl iodide $6 \mathbf{i}$ with a meta-MeO group gave the product with somewhat decreased selectivity (7i, $88: 12$ ) compared to the reaction with 4-iodoanisole (7h, 97:3). Aryl bromide is suitable for the coupling reaction as demonstrated by the formation of the desired product $7 \mathbf{h}$ in useful yield (62\%) with 4-bromoanisole as the reagent. Heteroaromatic iodide, such as 2-iodothiophene and 2-acetyl-5-iodothiophene,

Table 3 Palladium-catalyzed Hiyama-Denmark cross-couplings of (Z)vinylsilane with various aryl halides ${ }^{a}$

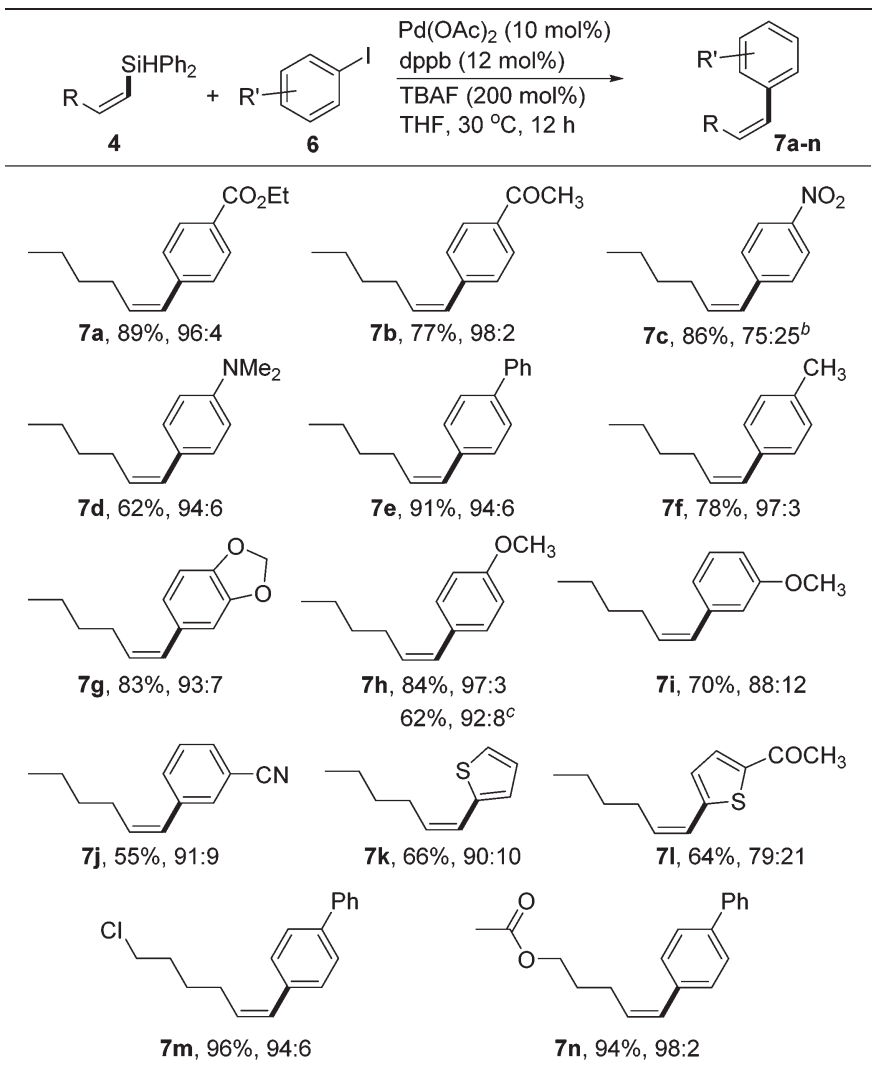

${ }^{a}$ Reaction conditions: $4 \mathbf{c}(0.24 \mathrm{mmol})$, aryl iodide $(0.2 \mathrm{mmol})$, TBAF $(0.4 \mathrm{mmol})$ in THF $(0.4 \mathrm{~mL})$. Yield of isolated products, unless otherwise noted. $Z / E$ ratios of isolated products were determined by GC. ${ }^{b}$ Without dppb, 24 h. ${ }^{c}$ Use 4-bromoanisole. Yield determined by ${ }^{1} \mathrm{H}$ NMR spectroscopy. 


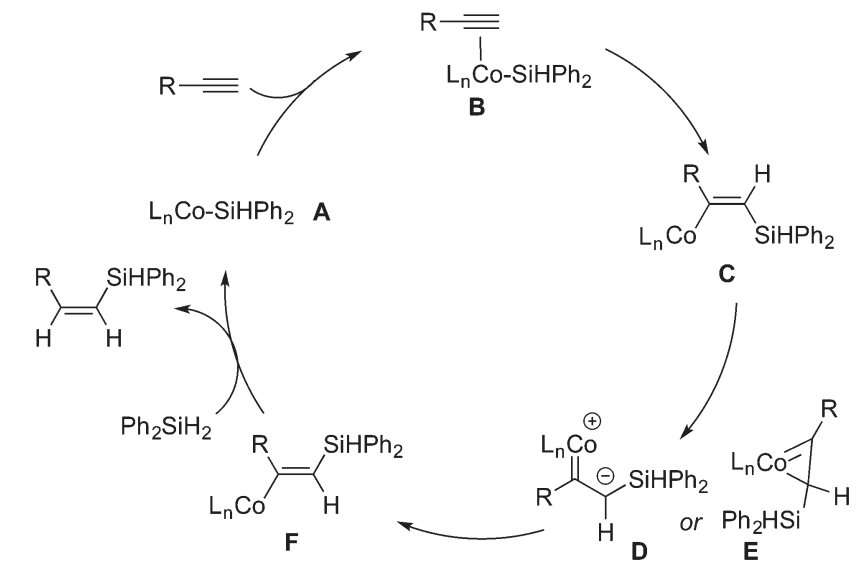

Scheme 2 Proposed mechanism involving the Ojima-Crabtree type rearrangement for Co-catalyzed (Z)-selective hydrosilylation of terminal alkynes.

gave the corresponding products $7 \mathbf{k}$ and $7 \mathbf{l}$ in 66 and $64 \%$ isolated yields, respectively. Functional $Z$-vinylsilanes such as $\mathbf{4 g}$ and 40 reacted with 4-iodo-1,1'-biphenyl under standard conditions and gave the corresponding $Z$-alkenes $\mathbf{7 m}$ and $\mathbf{7 n}$ in excellent yields and selectivities.

A mechanism accounting for the formation of (Z)- $\beta$-vinylsilane is presented in Scheme 2. On the basis of the precedents of Co-catalyzed hydrosilylation processes, ${ }^{11,16,17,21}$ we propose that the catalytic cycle involves a low-valent Co(I) silyl intermediate. The insertion of the coordinated terminal alkyne into the Co-Si bond forms a vinyl Co intermediate, (Z)-l-silyl-1alken-2-yl-cobalt (C). Due to the significant steric repulsion between the bulky silyl group and the metal moiety, complex $\mathbf{C}$ undergoes isomerization to form a sterically less demanding complex F, (E)-l-silyl-l-alken-2-yl-cobalt, through the OjimaCrabtree type rearrangement. ${ }^{4 h, 5 g}$ E then reacts with $\mathrm{Ph}_{2} \mathrm{SiH}_{2}$ to form $(Z)$-vinylsilane and regenerate the $\mathrm{Co}(\mathrm{I})$ silyl species $\mathbf{A}$.

\section{Conclusions}

In conclusion, we have developed a highly efficient cobalt-catalyzed regio- and stereoselective hydrosilylation of terminal alkynes with $\mathrm{Ph}_{2} \mathrm{SiH}_{2}$ to generate $(Z)$ - $\beta$-vinylsilanes with high functional group tolerance. The silyl groups introduced into the vinylsilane products offer flexible synthetic manipulations as demonstrated by the Hiyama-Denmark cross-couplings with aryl halides, allowing a convenient, stereoselective synthesis of Cis-disubstituted alkenes.

\section{Acknowledgements}

We gratefully acknowledge the financial support from the National Natural Science Foundation of China (No. 21272255, 21121062).

\section{Notes and references}

1 (a) H. Brunner, Angew. Chem., Int. Ed., 2004, 43, 2749; (b) B. M. Trost and Z. T. Ball, Synthesis, 2005, 853; (c) S. J. Clarson, Silicon, 2009, 1, 57; (d) D. S. W. Lim and E. A. Anderson, Synthesis, 2012, 983.

2 (a) T. H. Chan and I. Fleming, Synthesis, 1979, 761; (b) T. A. Blumenkopf and L. E. Overman, Chem. Rev., 1986, 86, 857; (c) E. Langkopf and D. Schinzer, Chem. Rev., 1995, 95, 1375; (d) I. Fleming, A. Barbero and D. Walter, Chem. Rev., 1997, 97, 2063.

3 (a) H. Aneetha, W. Wu and J. G. Verkade, Organometallics, 2005, 24, 2590; (b) G. De Bo, G. Berthon-Gelloz, B. Tinant and I. E. Markó, Organometallics, 2006, 25, 1881; (c) Y. Nakao, H. Imanaka, J. Chen, A. Yada and T. Hiyama, J. Organomet. Chem., 2007, 692, 585; (d) G. Berthon-Gelloz, J.-M. Schumers, G. De Bo and I. E. Markó, J. Org. Chem., 2008, 73, 4190; (e) A. Hamze, O. Provot, J.-D. Brion and M. Alami, J. Organomet. Chem., 2008, 693, 2789; (f) M. Blug, X.-F. Le Goff, N. Mézailles and P. Le Floch, Organometallics, 2009, 28, 2360; $(g)$ R. Cano, M. Yus and D. J. Ramón, ACS Catal., 2012, 2, 1070; (h) K. Igawa, D. Yoshihiro, N. Ichikawa, N. Kokan and K. Tomooka, Angew. Chem., Int. Ed., 2012, 51, 12745; (i) S. Dierick, E. Vercruysse, G. Berthon-Gelloz and I. E. Markó, Chem. Eur.J., 2015, 21, 17073; (j) D. Munz, C. Allolio, D. Meyer, M. Micksch, L. Roessner and T. Strassner, J. Organomet. Chem., 2015, 794, 330; ( $k$ ) L. Ortega-Moreno, R. Peloso, C. Maya, A. Suarez and E. Carmona, Chem. Commun., 2015, 51, 17008.

4 (a) M. Atsunori, T. Eisuke, K. Hiroshi, H. Kazunori, N. Yasushi and H. Tamejiro, Chem. Lett., 1998, 27, 443; (b) J. W. Faller and D. G. D'Alliessi, Organometallics, 2002, 21, 1743; (c) A. Mori, E. Takahisa, Y. Yamamura, T. Kato, A. P. Mudalige, H. Kajiro, K. Hirabayashi, Y. Nishihara and T. Hiyama, Organometallics, 2004, 23, 1755; (d) M. V. Jiménez, J. J. Pérez-Torrente, M. I. Bartolomé, V. Gierz, F. J. Lahoz and L. A. Oro, Organometallics, 2008, 27, 224; (e) J. L. McBee, J. Escalada and T. D. Tilley, J. Am. Chem. Soc., 2009, 131, 12703; $(f)$ M. Iglesias, M. PerezNicolas, P. J. S. Miguel, V. Polo, F. J. Fernandez-Alvarez, J. J. Perez-Torrente and L. A. Oro, Chem. Commun., 2012, 48, 9480; $(g)$ M. Iglesias, P. J. Sanz Miguel, V. Polo, F. J. Fernández-Alvarez, J. J. Pérez-Torrente and L. A. Oro, Chem. - Eur.J., 2013, 19, 17559; (h) I. Ojima, N. Clos, R. J. Donovan and P. Ingallina, Organometallics, 1990, 9, 3127.

5 (a) C.-H. Jun and R. H. Crabtree, J. Organomet. Chem., 1993, 447, 177; (b) M. Viciano, E. Mas-Marzá, M. Sanaú and E. Peris, Organometallics, 2006, 25, 3063; (c) M. Yoshihiro, I. Eigo and I. Masahiko, Chem. Lett., 2006, 35, 836; (d) V. S. Sridevi, W. Y. Fan and W. K. Leong, Organometallics, 2007, 26, 1157; (e) A. Zanardi, E. Peris and J. A. Mata, New J. Chem., 2008, 32, 120; $(f)$ J. J. PérezTorrente, D. H. Nguyen, M. V. Jiménez, F. J. Modrego, R. Puerta-Oteo, D. Gómez-Bautista, M. Iglesias and 
L. A. Oro, Organometallics, 2016, 35, 2410; $(g)$ R. S. Tanke and R. H. Crabtree, J. Am. Chem. Soc., 1990, 112, 7984.

6 (a) M. A. Esteruelas, J. Herrero and L. A. Oro, Organometallics, 1993, 12, 2377; (b) H. Katayama, K. Taniguchi, M. Kobayashi, T. Sagawa, T. Minami and F. Ozawa, J. Organomet. Chem., 2002, 645, 192; (c) C. S. Arico and L. R. Cox, Org. Biomol. Chem., 2004, 2, 2558; (d) S. V. Maifeld, M. N. Tran and D. Lee, Tetrahedron Lett., 2005, 46, 105; (e) C. Menozzi, P. I. Dalko and J. Cossy, J. Org. Chem., 2005, 70, 10717; $(f)$ M. Nagao, K. Asano, K. Umeda, H. Katayama and F. Ozawa, J. Org. Chem., 2005, 70, 10511; $(g)$ R. Gao, D. R. Pahls, T. R. Cundari and C. S. Yi, Organometallics, 2014, 33, 6937; $(h)$ C. Conifer, C. Gunanathan, T. Rinesch, M. Hölscher and W. Leitner, Eur. J. Inorg. Chem., 2015, 333; (i) Y. Na and S. Chang, Org. Lett., 2000, 2, 1887.

7 (a) K. Junge, K. Schroder and M. Beller, Chem. Commun., 2011, 47, 4849; (b) B. D. Sherry and A. Fürstner, Acc. Chem. Res., 2008, 41, 1500; (c) I. Bauer and H.-J. Knölker, Chem. Rev., 2015, 115, 3170; (d) M. D. Greenhalgh, A. S. Jones and S. P. Thomas, ChemCatChem, 2015, 7, 190; (e) J. Sun and L. Deng, ACS Catal., 2016, 6, 290; $(f)$ X. Du and Z. Huang, ACS Catal., 2017, 1227.

8 (a) S. C. Bart, E. Lobkovsky and P. J. Chirik, J. Am. Chem. Soc., 2004, 126, 13794; (b) C. Belger and B. Plietker, Chem. Commun., 2012, 48, 5419; (c) M. D. Greenhalgh, D. J. Frank and S. P. Thomas, Adv. Synth. Catal., 2014, 356, 584; (d) A. J. Challinor, M. Calin, G. S. Nichol, N. B. Carter and S. P. Thomas, Adv. Synth. Catal., 2016, 358, 2404.

9 (a) M. Isobe, R. Nishizawa, T. Nishikawa and K. Yoza, Tetrahedron Lett., 1999, 40, 6927; (b) L. Yong, K. Kirleis and H. Butenschön, Adv. Synth. Catal., 2006, 348, 833; (c) T. Konno, K.-i. Taku, S. Yamada, K. Moriyasu and T. Ishihara, Org. Biomol. Chem., 2009, 7, 1167; (d) K.-H. Huang and M. Isobe, Eur. J. Org. Chem., 2014, 4733; (e) A. Rivera-Hernández, B. J. Fallon, S. Ventre, C. Simon, M.-H. Tremblay, G. Gontard, E. Derat, M. Amatore, C. Aubert and M. Petit, Org. Lett., 2016, 18, 4242 .
10 (a) T. Bartik, G. Nagy, P. Kvintovics and B. Happ, J. Organomet. Chem., 1993, 453, 29; (b) A. Tillack, S. Pulst, W. Baumann, H. Baudisch, K. Kortus and U. Rosenthal, J. Organomet. Chem., 1997, 532, 117; (c) M. R. Chaulagain, G. M. Mahandru and J. Montgomery, Tetrahedron, 2006, 62, 7560; (d) J. Berding, J. A. van Paridon, V. H. S. van Rixel and E. Bouwman, Eur. J. Inorg. Chem., 2011, 2450.

11 Z. Mo, J. Xiao, Y. Gao and L. Deng, J. Am. Chem. Soc., 2014, 136, 17414.

12 J. H. Docherty, J. Peng, A. P. Dominey and S. P. Thomas, Nat. Chem., 2017, DOI: 10.1038/nchem.2697.

13 (a) J. Guo and Z. Lu, Angew. Chem., Int. Ed., 2016, 55, 10835; (b) J. Guo, X. Shen and Z. Lu, Angew. Chem., Int. Ed., 2017, 56, 615.

14 Z. Zuo, J. Yang and Z. Huang, Angew. Chem., Int. Ed., 2016, $\mathbf{5 5}, 10839$.

15 Note that $(Z)-\beta$-selective hydroboration of terminal alkynes has been previously reported by Chirik et al. See: J. V. Obligacion, J. M. Neely, A. N. Yazdani, I. Pappas and P. J. Chirik, J. Am. Chem. Soc., 2015, 137, 5855.

16 W. J. Teo, C. Wang, Y. W. Tan and S. Ge, Angew. Chem., Int. Ed., 2017, 56, 4328.

17 X. Du, Y. Zhang, D. Peng and Z. Huang, Angew. Chem., Int. Ed., 2016, 55, 6671.

18 (a) S. E. Denmark and J. H. C. Liu, Angew. Chem., Int. Ed., 2010, 49, 2978; (b) Y. Nakao and T. Hiyama, Chem. Soc. Rev., 2011, 40, 4893; (c) H. F. Sore, W. R. J. D. Galloway and D. R. Spring, Chem. Soc. Rev., 2012, 41, 1845; (d) S. E. Denmark and A. Ambrosi, Org. Process Res. Dev., 2015, 19, 982; (e) T. Komiyama, Y. Minami and T. Hiyama, ACS Catal., 2017, 7, 631.

19 C. Cheng, E. M. Simmons and J. F. Hartwig, Angew. Chem., Int. Ed., 2013, 52, 8984.

$20 \mathrm{Lu}$ reported cross-couplings of two diphenyl-substituted $\alpha$-vinylsilanes with aryl iodide using $\mathrm{Pd}_{2}(\mathrm{dba})_{3}$ as the catalyst. See ref. 13.

21 C. C. H. Atienza, T. Diao, K. J. Weller, S. A. Nye, K. M. Lewis, J. G. P. Delis, J. L. Boyer, A. K. Roy and P. J. Chirik, J. Am. Chem. Soc., 2014, 136, 12108. 